\title{
Гендерное равенство как фактор профессиональной карьеры в сфере науки и технологий ${ }^{1}$
}

\author{
И.П. ПОПОВА*
}

\begin{abstract}
*Ирина Петровна Попова - кандидат социологических наук, ведущий научный сотрудник, Институт социологии ФНИСЦ РАН. Адрес: 117218, Москва, ул. Кржижановского, д. 24/35, к. 5. E-mail: irina_popova@list.ru

Цитирование: Попова И.П. (2021) Гендерное равенство как фактор профессиональной карьеры в сфере науки и технологий // Мир России. Т. 30. № 2. С. 98-122. DOI: $10.17323 / 1811-038 X-2021-30-2-98-122$
\end{abstract}

В статье рассматриваются характеристики профессиональных карьер в сфере науки и технологий с позиций гендерного равенства и справедливости в занятости. Анализ опирается на подходы к исследованиям карьер в этой сфере, фокусирующиеся на структурных условиях и контекстах формирования карьер. Одним из факторов этих условий становятся современные программы и инициативы в сфере науки и технологий, учитьваюшие гендерное равенство в профессиональной карьере на международном уровне и на уровне национальных государств (анализируются данные до марта 2020 г.). В этой связи привлекаются подходы, обосновывающие гендерную справедливость (capabilities арргоасh), вопросы так называемой позитивной дискриминации в отношении занятости и профессионального продвижения в этой сфере. Анализируются аспекты организации научной карьеры, которые в биографических нарративах ученых осознаются и переосмысливаются как проявления гендерного неравенства под влиянием опыта знакомства с программами в рамках политики гендерного равенства в научной деятельности. Эмпирической базой анализа, позволяющей понять влияние и оченки этих программ, являются нарративно-биографические полуструктурированные интервью с ученыли естественно-научных дисциплин (N=40, 2018-2019 г2.). Оиенки проявлений гендерного неравенства касаются трудоустройства, распределения ролей в коллективе в соответствии с неформальными нормами, сочетания профессиональных и семейных ролей. Анализ позволяет заключить, что в отночении гендерного неравенства в сфере занятости в науке, прояв-

\footnotetext{
1 Исследование выполнено при финансовой поддержке РФФИ и Академии общественных наук Китая в рамках научного проекта № 19-511-93003.
} 
ления которого часто остаются незамеченными, актуальнылм становится формирование возможностей их осознания и оценки самими учеными, регулируемое инструментами научной политики. В то же время институциональная поддержка гендерного равенства должна происходить во взаимосвязи с поддержкой статуса и перспектив российской науки в иелом.

Ключевые слова: профессиональная карьера, исследования карьер, справедливость, гендер, гендерное равенство, наука и технологии, позитивная дискриминациия, научная политика

\section{Постановка проблемы}

Гендерное равенство в занятости в современных обществах актуализируется с точки зрения создания новых возможностей в модернизации социально-экономической сферы в целом, в т. ч. сферы науки и технологий ${ }^{2}$ В связи с этим одним из вопросов становится создание условий профессиональной карьеры в сфере науки и технологий, принимающих во внимание гендерные аспекты занятости в ней. Эти условия складываются в комплексе поддерживающих формирование новых моделей воспроизводства кадров в науке контекстов и структур - карьерных инфраструктурах. Можно выделить различные уровни этого комплекса: макроуровень, который определяется национальной научно-технической политикой; средний уровень, где учитываются условия внутри организации; уровень влияния близкого окружения и семьи, специфика исследования которых концентрирует ресурсы различных дисциплин, в т. ч. гендерных исследований [Попова 2017]. В последние десятилетия более влиятельным становится глобальный, или международный, уровень, связанный, с одной стороны, с растущей международной мобильностью занятых в сфере науки и технологий специалистов, а с другой стороны, с выработкой общих принципов ее развития в научной политике разных стран, включая проблематику гендерного равенства.

Различные стороны этих подходов рассматриваются через воздействие на профессиональное развитие и модели карьеры в науке международных направлений, инициатив и программ деятельности. Эти подходы активно обсуждаются, а некоторые из них подвергаются серьезной критике. В меньшей степени исследуется непосредственное влияние этих программ на судьбы и карьерные траектории самих специалистов, занятых в этой сфере, на восприятие и оценку ими тех или иных их проявлений в собственном профессиональном поле деятельности.

Хотелось бы пояснить интерес к постановке исследовательской задачи именно в последнем направлении. Он определился в ходе исследования «Профессиональная карьера как фактор воспроизводства профессиональных групп в сфере

\footnotetext{
2 Сфера науки и технологий (или науки и техники, англ. - fields of science and technology, или $S \& T$ ) - широко принятое международное определение сферы НИОКР, в т. ч. для целей международной стандартизации и статистики; в нее включены естественные и технические науки, а также социальные и гуманитарные (cм.: https://www.un.org). В нашем исследовании опрашивались респонденты - научные работники естественно-научных дисциплин.
} 
науки и технологий», проведенного при поддержке РГНФ/РФФИЗ с учеными, которые работали или работают за рубежом. Первые интервью сразу показали, что осознаваемые и актуализируемые проблемы гендерного неравенства и связанной с этим справедливости в занятости и профессиональном продвижении неожиданно вышли на одно из заметных мест в профессиональных биографиях. И это стало их явной отличительной чертой: в биографических нарративах ученых, работающих в российских организациях, эти темы спонтанно не возникали. Такое различие в отношении к практически одинаковым ситуациям показало, что характерные для них проблемы могут быть неосознаваемыми, но важными, и их значимость становится очевидной главным образом под воздействием определенных внешних условий. Это в свою очередь побудило более детально разобраться в причинах такого различия и в характере обусловленности ${ }^{4}$. Так в исследовании выделилась тема влияния подходов гендерного равенства в международных институтах, инициативах, программах в качестве факторов воздействия на формирование профессиональных карьер ученых в S\&T.

В статье делается попытка проанализировать взаимосвязь вопросов профессиональной карьеры, гендерного равенства и справедливости в занятости через изучение возможностей, предоставляемых гендерно ориентированными программами в сфере науки и технологий, и оценку их проявлений самими учеными. Общее направление этой взаимосвязи определяют междисциплинарные исследования карьеры, важной составляющей которых являются гендерные исследовательские подходы, направленные на оценку новых возможностей в профессиональном продвижении в связи с политикой гендерного равенства. Соответственно, анализ сосредотачивается прежде всего на характеристиках условий формирования научных карьер с позиций гендерного равенства в научной политике как фактора макроуровня; далее рассматриваются основные характеристики международных программ в сфере научной политики, а также аспекты восприятия действия этих программ российскими учеными естественно-научных дисциплин 5 .

\section{Профессиональная карьера в сфере науки и технологий с точки зрения гендерного равенства}

Гендерная проблематика научной карьеры - это объект разнообразного в дисциплинарном отношении исследовательского направления. Для нашей работы интерес представляют научные подходы, рассматривающие диспропорции в возможностях осуществлять равноправие в занятости, создаваемые также и социокультурными условиями; возможности и влияние политики, различных программ на уровне государства, научного сообщества на трансформацию или корректировку этих условий; поведение и мотивацию занятых в науке женщин под влиянием формальных

\footnotetext{
3 Эмпирическая база: нарративно-биографические полуструктурированные интервью с учеными естественнонаучных дисциплин ( $\mathrm{N}=40$, время проведения интервью-2018-2019 гг.).

4 В план интервью были добавлены уточнения о гендерных аспектах занятости и карьеры.

5 Следует заметить, что статья была сдана в редакцию журнала в феврале 2020 г., что объясняет отсутствие в анализе более поздних изменений.
} 
и неформальных норм на их рабочих местах, необходимости совмещения ролей в профессиональной деятельности и семье.

Обратимся к некоторым характеристикам неравномерной представленности женщин в иерархических срезах сферы научной деятельности в глобальном плане, особенно в естественно-научной и инженерной деятельности. С тех времен, когда наука была делом исключительно мужским, ситуация изменилась кардинально, но карьера остается гендерно асимметричной: несмотря на достижение равных или близких пропорций количества женщин и мужчин в науке, властные позиции в иерархических научных структурах занимают в основном мужчины. Это демонстрируют данные международной статистики и статистики в отдельных странах, в т. ч. в России (несмотря на более продолжительный, чем в западных странах, период закрепленного на законодательном уровне равенства в доступе к занятию научной деятельностью для мужчин и женщин). Эти показатели свидетельствуют о том, что феномен leaky pipeline (или «дырявого трубопровода») относительно карьеры, символизирующий снижение доли женщин в науке по мере роста статусов [Blickenstaff 2005, Dubois-Shaik, Fusulier 2015], остается универсальным международным феноменом с теми или иными вариациями по странам.

Проблема недопредставленности женщин в различных сферах науки, влияющей на снижение в целом их статуса, рассматривается как актуальная не только с точки зрения их прав и возможностей индивидуальной реализации талантов, но и как потенциальный риск для общества с точки зрения неравных возможностей (в силу более низкого статусного положения) влиять на принятие ключевых политических решений по жизненно важным проблемам (например, изменения климата в мире). Женщины составляют меньшинство в области разработки политики и соответствующих программ, в то же время их позиции в отношении влияния этих изменений, которые существенно отличаются от позиций мужчин именно ввиду более низкого социально-экономического статуса, особенно значимы для общества в целом [Хьюэр 2015]. Этот властно-политический аспект важно подчеркнуть в рамках нашего исследования, связанного с анализом социального конструирования возможностей профессионального и статусного развития в сфере науки и технологий.

Начиная с 1990-х гг. в России к вопросам, касающимся гендерной асимметрии в научных иерархиях и структурах, добавились проблемы кризиса в науке: именно тогда произошло разрушение прежних моделей воспроизводства кадров и, соответственно, типов профессиональных карьер, что актуализирует тему новых форматов для более эффективной организации деятельности. Неравномерная представленность женщин в сфере науки и технологий, прежде всего в отношении статусных иерархий, отмечалась и в предыдущий период - во время быстрого роста этой сферы в СССР в 1960-1980-е гг. Так, к концу 1980-х гг. удельный вес женщин в составе научных работников был существенно выше, чем в мире в целом - примерно 40\% всех научных работников страны, однако тенденция снижения доли женщин по мере роста квалификации сохранялась: например, в 1986 г. доля женщин в общем числе кандидатов наук составляла 28\%, докторов наук - 13\% [Келле, Кугель 1991, с. 86-89]. В современных условиях этот тренд становится более глубоким. Относительно карьеры это очевидно по следующим общим данным, характеризующим сужение доли женщин по мере повышения статуса: среди имеющих высшее образование, включая послевузовское, доля женщин 
значительно больше (58\%) (по данным Всероссийской переписи 2010 г. [Женщины и мужчины 2018, с. 71$])^{6}$; среди кандидатов наук и докторов наук она существенно уменьшается (таблицуа 1).

Таблица 1. Исследователи, имеющие ученую степень доктора или кандидата наук, выполняющие научные исследования и разработки, \%

\begin{tabular}{|l|c|c|c|c|c|c|c|c|c|c|}
\hline \multirow{2}{*}{ Категории } & \multicolumn{2}{|c|}{2000} & \multicolumn{2}{c|}{2005} & \multicolumn{2}{c|}{2010} & \multicolumn{2}{c|}{2015} & \multicolumn{2}{c|}{2017} \\
\cline { 2 - 13 } & жен. & муж. & жен. & муж. & жен. & муж. & жен. & муж. & жен. & муж. \\
\hline Кандидаты наук & 34 & 66 & 36 & 64 & 39 & 61 & 42 & 58 & 42 & 58 \\
\hline Доктора наук & 19 & 81 & 21 & 79 & 23 & 77 & 26 & 74 & 26 & 74 \\
\hline
\end{tabular}

Источник: [Женщины и мужчины 2018, с. 85].

На фоне примерно равных пропорций занятости мужчин и женщин в целом по стране, а также превышения почти вдвое числа женщин, занятых в качестве специалистов высшего уровня квалификации, в сфере науки и техники женщин значительно меньше, чем мужчин (таблиц̧а 2).

Таблица 2. Численность занятых по полу и группам занятий в 2018 г., тыс. чел.

\begin{tabular}{|c|c|c|c|}
\hline \multirow{2}{*}{ Занятые } & всего & мужчины & женщины \\
\hline & 72532 & 37259 & 35272 \\
\hline Специалисты высшего уровня квалификации: всего & 17819 & 6472 & 11347 \\
\hline в области науки и техники & 3162 & 2191 & 971 \\
\hline Специалисты среднего уровня квалификации: всего & 9390 & 3772 & 5618 \\
\hline в области науки и техники & 2611 & 2131 & 480 \\
\hline
\end{tabular}

Источник: [Труд и занятость в России 2019, с. 32].

Общие статистические тенденции выражаются в уменьшении удельного веса женщин в науке в целом, в т. ч. в общественных и гуманитарных и особенно интенсивно - в естественных науках ${ }^{7}$. Однако эти тенденции могут не восприниматься как актуальные на фоне продолжающегося сокращения числа исследователей в целом, затрагивающего и женщин, и мужчин, их остающегося невысоким статуса в обществе. Обвальный характер это снижение носило в первой половине 1990-х гг.: в 1990 г. в РФ насчитывалось 1943432 занятых в науке в целом

\footnotetext{
6 Среди женщин в 2018 г. доля имеющих высшее образование составляла 38,1\%, а среди мужчин - 29,3\% [Труд и занятость в России 2019, с. 20].

7 См.: Шматко Н., Волкова Г. (2018) Наука и https://www.hse.ru/monitoring/mnk/press/216935310.html
} 
(в т. ч. 1227388 исследователей и техников), в 1996 г. - 990743 в целом, включая 572565 исследователей и техников ${ }^{8}$. Эта тенденция продолжается: с 2000 по 2018 г. численность персонала, занятого исследованиями и разработками, сократилась с 887729 до 682580 чел., в т. ч. исследователей - с 425954 до 347854 чел. ${ }^{9}$

В то же время снижение доли женщин в науке в России в последние годы идет вразрез с тенденцией ее роста в мировом масштабе: так, в странах ЕС, где женщины составляли $33 \%$ от общего количества ученых, их количество в 2000 -х гг. увеличивалось быстрее, чем коллег мужского пола (на 5,1\% в год в 2002-2009 гг. по сравнению с 3,3\% для мужчин), так же как и среди ученых и инженеров (до 5,4\% ежегодно в период с 2002 по 2010 г., по сравнению с 3,1\% для мужчин) [Хьюэр 2015, с. 95-96]. В международных сравнениях доля занятости женщин в науке в России - одна из высоких, что характерно и для стран Восточной Европы бывшего социалистического лагеря, и ее сокращение с 1990-х гг. вызывает опасения прежде всего в потерях этих преимуществ [Хьюэр 2015].

Такое положение дел стимулирует большее количество исследований различных аспектов гендерного неравенства в занятости в науке: проблемы дискриминации по признаку пола, лидерство, личностно-профессиональные взаимодействия, двойная карьера - балансирование между карьерой и ролями в семье. Барьеры в профессиональном продвижении исследуются в связи с гендерной сегрегацией и дискриминацией на рынке труда, ограничениями в карьере в определенных профессиях, формальными и неформальными, социокультурными стереотипами в отношении профессий и т. д.

В рамках нашего исследования мы выделим методологические подходы, пересечение которых определяется общей целью выработки мер политики гендерного равенства: это проблематика социального контекста в исследованиях карьер и анализ гендерного неравенства в сфере занятости с позиций гендерной справедливости в развитие подхода социальных и функциональных возможностей.

Мы опираемся на сформулированные нами ранее представления, во-первых, о профессиональной карьере в сфере науки и технологий, которые базируются на понимании ее долговременного и последовательного, ориентированного на достижение профессионального статуса развития, основанного на ресурсах и структурах внешней среды; во-вторых, об инфраструктуре карьеры как конструируемом благоприятном социальном контексте на различных уровнях [Попова 2017, с. 128]. Исходя из этого, гендерные аспекты научной карьеры могут рассматриваться как часть этого контекста и объект в процессах его формирования, в т. ч. на уровне национальной научной политики. Такой подход согласуется с тенденциями в рамках междисциплинарного направления исследований карьер, фокусирующегося на структурных условиях и контекстах их формирования. Гендерные иерархии рассматриваются как их часть, а измерения этих иерархий опираются также на представления индивидов о соотношении полов на руководящих должностях [Lawrence 2011, p. 62]. Динамический аспект связан с вниманием к взаимодействию структур и действий акторов в исследовании карьер через концепт карьерных сценариев, которые, с одной стороны, формируются под влиянием существующих

\footnotetext{
8 Наука и инновации (1997) // Российский статистический ежегодник 1997. С. 502 // http://istmat.info/files/uploads/45329/18nauka_i_innovacii.pdf

9 Данные Госкомстата за 2019 г. (см.: gks.ru).
} 
институциональных норм и правил, а с другой, способствуют изменению контекста через формирование новых образцов карьер [Duberley et al. 2006]. Развитие этих подходов приводит к концептуализации взаимосвязи между социальным контекстом как макроструктурой (мезоструктурой), формирующей карьерные возможности и карьерные цели акторов, и карьерным поведением (действием) [Andersen et al. 2019]. В нашем исследовании эти взгляды представляют интерес с точки зрения фокусирования на том, как под воздействием личного карьерного опыта изменяются представления ученых о нормах и условиях их занятости при соотнесении с отличающимися условиями и контекстами (в России и за рубежом).

Для достижения этой цели важен следующий подход, обосновывающий принципы гендерной справедливости. Основная идея, заложенная в нем, исходит из нормативных представлений о правах человека [Nussbaum 2016] и развивается под влиянием политической практики последних десятилетий, направленной на снижение неравенства и дискриминации в гендерном отношении в сфере занятости. Наиболее распространенные и влиятельные концепции связываются с подходами гендерной справедливости, возможностей развития (capability/ies approach), которые рассматривались А. Сеном в рамках концепций благосостояния ${ }^{10}$. При разработке этих подходов в отношении гендерного неравенства он подчеркивал важность ресурсов и возможностей для раскрытия способностей женщин как противовеса дискриминации. Обращаясь к конкретным вопросам справедливости, А. Сен подчеркивал мысль о том, что традиционные представления о роли женщин часто интернализируются самими женщинами как «естественные». Он анализировал преимущества подхода возможностей (функциональных, социальных), с его потенциалом противостояния таким предрассудкам, в сравнении с другими теориями справедливости: концепциями либерализма и экономического утилитаризма [Sen 1995]. М. Нуссбаум подчеркивала важность этого подхода как релевантного при обсуждении проблем гендерной справедливости и развития нормативной гендерной перспективы [Nussbaum 2003]. Этот подход получил широкую известность, и к нему обращаются в более широких теоретических рамках проблем справедливости, рассматривая концептуальные принципы человеческого развития и человеческого потенциала с точки зрения формирования условий для их применения в политических программах на разных уровнях. Его использование анализируется в целях концептуализации и конкретной оценки гендерного неравенства. Такой подход к оценке уровня и мер социальной справедливости рассматривается как более объективный, т. к. опирается не на самооценку положения (человек может привыкнуть к своему положению и даже оправдывать его), а на наличие объективных возможностей (потенциала) улучшить его, что может не осознаваться, оставаться незамеченным. Отметим, что для оценки гендерных неравенств в сфере занятости важно учитывать широкий контекст неравенств в различных сферах жизни, определяющих неравенство в функциональных возможностях [Robeyns 2003]. Этот подход позволяет концептуализировать механизмы социальной политики в плане преобразования возможностей и способностей людей в деятельность по улучшению качества жизни [Hobson 2018]. В его свете исследование

\footnotetext{
10 Этот подход рассматривается в рамках понимания социальной политики как основной политики «человеческого развития» и «приобретаемых способностей» (capabilities), под которыми понимается совокупность жизненных сил и средств [Черныш 2020, с. 9].
} 
угнетаемых, например женщин, занятых в сфере науки и технологий, позволяет глубже понимать природу неравенства и перспективы эффективности его снижения [Kameshwara, Shukla 2017]. При этом важно учитывать широкие перспективы этого подхода с точки зрения социальной справедливости в целом для конструирования социальной политики государства, направленной на предоставление важнейших человеческих возможностей и ресурсов, которые определяют полноценное функционирование каждого человеческого существа [Канари 2019, с. 66], поддержание человеческого достоинства [Черныш 2020].

Таким образом, карьера в сфере науки и технологий анализируется с позиций выравнивания возможностей занятых в ней женщин и мужчин через создание более справедливых условий их профессиональной деятельности и профессионального развития благодаря различным мерам политики в этой сфере. Подчеркнем, что гендерное равенство при этом рассматривается как универсальный принцип политики соблюдения прав человека, нацеленной на создание предпосылок для равного доступа к экономическим и социальным ресурсам, выравнивания гендерных структур занятости и политического представительства мужчин и женщин [Рощин, Зубаревич 2005]. Исходя из этого, гендерное равенство, как модерирующий принцип политики при обосновании справедливых условий для занятости и профессионального развития в науке, актуализирует несколько направлений исследования.

Прежде всего, это анализ практики позитивной дискриминации (affirmative/ positive action), которая стала популярной во всем мире со второй половины XX в. Она служит идее выравнивания возможностей, их сбалансированности в рамках обоснования принципов дистрибутивной справедливости. В их основе - постулаты паритета, равного представительства дискриминированных групп в профессиональной и политической жизни с учетом исторически сформировавшихся дискриминаций [Штомпка 2017, с. 391]. В настоящее время позитивная дискриминация чаще всего понимается с точки зрения оказания содействия «лишенным преимуществ» людям для перехода на лучшую работу, в обоснование этого понимания включаются идеи компенсирующей справедливости [Тарусина, Исаева 2013, с. 53-54]. В качестве критериев лишенных преимуществ групп рассматривались этнические и расовые, а также гендерные критерии. В целом эти подходы воспринимаются весьма противоречиво, встречая как стремление к обоснованию и оправданию, так и критику с точки зрения генерации (потенциальной и реальной) новых неравенств.

Принципы и практика внедрения позитивной дискриминации оцениваются неоднозначно, в т. ч. в научном сообществе. Вероятно, это влияет на снижение интереса к идее гендерного равенства и гендерной справедливости в общественном мнении, которое фиксируют некоторые исследования. На практике же в организациях и коллективах с традиционным преимущественно мужским представительством наблюдаются различные меры в обход этих норм, формально учитываемые как выполнение предписаний, но на самом деле имеющие показной характер (например, феномен токенизма в практиках занятости в мужских коллективах, фактически обесценивающих эти нормы в отношении квот для женщин [Здравомыслова, Темкина 2015, с. 489]).

Другое направление - это анализ культурных и структурных барьеров, связанных с источниками гендерных неравенств в науке. Их исследования также вносят 
вклад в формирование институтов и программ политики гендерного равенства, влияющего на контекст научной профессиональной карьеры в мире и в нашей стране.

Соииокультурные условия продвижения в сфере науки связаны с тем, что наука лишь недавно стала открытой не только для перспектив профессионального продвижения, но и для занятости вообще. Ярким примером может служить Россия 1920-х гг., которая одной из первых предоставила женщинам право заниматься наукой [Долгова, Стрельцуова 2019], что стало значительным шагом вперед по сравнению с тем положением дел, когда женщины в науке стигматизировались (запреты на посещение лекций и укоренившиеся негативные представления об «ученых дамах») [Агамова, Аллахвердян 2000; Богданова 2004; Пушкарева 2017].

Барьеры в карьерном продвижении, связаннье со стереотипами и принятьми нормами, до сих пор остаются для женщин весьма существенными. Один из наиболее существенных связан с самим принятием в качестве эталонного образца мужской модели карьеры, свободной от личных обстоятельств, семейной ответственности и бремени домашней работы [Cuzzocrea, Luyon 2011]. Их формируют структуры, которые чрезмерно детерминируют карьерные результаты и устанавливают в зависимости от них нормы карьерных моделей. Это ведет к тому, что многие обстоятельства занятости женщин, связанные с совмещением ролей в семье (прежде всего роли матери), воспринимаются как второстепенные, лишь создающие помехи, что сужает возможности, например, учитывать в контрактах обстоятельства декретного отпуска по уходу за ребенком и создавать гибкие модели такой занятости. Совмещение материнства и научной (университетской) карьеры - значительное структурное препятствие, которое обсуждается в различных аспектах, например, с точки зрения баланса между семьей и работой [Грицай 2011; Рождественская 2019]. Следует отметить, что модели исполнения семейных ролей в условиях кризиса российской науки в 1990-2000-е гг. проявились достаточно специфично: не было возможности сочетать их с профессиональными обязанностями не только женщинам (роль матери), но и мужчинам (роль кормильца семьи). Это создавало «двойной» барьер в профессиональном и карьерном развитии самих ученых и научных коллективов, что на фоне кризиса в науке и падения статуса ученого привело к уходу молодежи из этой сферы [Попова 2016].

Другой серьезный барьер в профессиональном продвижении - более низкие институциональные возможности ввиду гендерной сегрегации при выборе этой перспективы в связи, например, с принятым устройством образовательных или дисциплинарных структур [Devine 1992; Xie Yu, Shauman 2003; Mann, DiPrete 2013; Ecklund, Lincoln, Tansey 2012]. Следует отметить ограничения, связанные с организационными культурами, среди которых - сложности из-за определенных предубеждений в оценке профессиональных заслуг женщин по сравнению с мужчинами, а также принятая во многих смешанных коллективах культура взаимоотношений, допускающая несерьезное отношение коллег-мужчин к коллегам-женщинам. Так, исследования выявляют влияние на карьеру «сексуализированной воспринимаемости» женщин в коллективах с преобладанием мужчин; при этом коллективные усилия женщин по обеспечению благоприятного представительства своей группы приводят к воспроизводству неявного, но мощного предписывающего гендерного стереотипа, который сдерживает их карьерный рост [Dulini at al. 2019]. Нормы и стереотипы в отношении карьерных иерархий характерны для всех обществ, хотя имеются и вариации. Так, исследование, проведенное в одном из университетов 
в КНР, показало, что барьеры перед женщинами-преподавателями в карьерном продвижении, общие для всех культур: двойная работа, стеклянный потолок, так называемый клуб мальчиков и социальная изоляция - дополняются специфическими для данного национального контекста ограничениями в роли женщин при принятии важных кадровых решений, влияющими на продвижение по службе [Rhoads, $G u$ 2012]. Анализ препятствий, затрудняющих деятельность женщин-руководителей в $\mathrm{SET}^{11}$, раскрывает сильное сдерживающее давление на нее неформальной организационной культуры мужских коллективов (сетей поддержки, которые являются традиционно мужскими, так называемой пивной культуры, в рамках которых формируются многие управленческие решения); женщинам-лидерам трудно разделять неформальные нормы этой культуры и нетворкинга, что снижает эффективность их стиля руководства (см. исследования в Германии: [Sagebiel 2014]).

Накопление разнообразного международного опыта исследований проблем гендерного равенства в сфере науки сопровождается ростом числа практических программ, инициатив, мер в этой сфере, имеющих также международный характер.

\section{Программы гендерного равенства в научно-техническом развитии как фактор карьерных возможностей}

Создание условий, смягчающих гендерное неравенство в науке, - неравномерный и противоречивый процесс, формирующий многоуровневую среду. Основные подходы, продвигаемые ООН с середины XX в. для защиты интересов женщин через разработку международно-правовых документов ${ }^{12}$, легли в основу национальных механизмов социальной политики и ее реализации в правовом, организационном, содержательном измерениях [Воронина 2008, с. 11; Гнедаш 2016]. Законодательно и институционально стали закрепляться принципы позитивной дискриминации: так, в Конвенции ООН о ликвидации всех форм дискриминации в отношении женщин отмечается, что «принятие государствами < ..> временных специальных мер, направленных на ускорение установления фактического равенства между мужчинами и женщинами, не считается <..> дискриминационным, однако оно ни в коей мере не должно влечь за собой сохранение неравноправных иди дифференцированных стандартов; эти меры должны быть отменены, когда будут достигнуты цели равенства возможностей и равноправного отношения» ${ }^{13}$, т. е. Конвенция допускает специальные меры (в виде позитивной дискриминации или квотирования), равно как и «принятие государствами-участниками специальных мер, направленных на охрану материнства», и не считает их дискриминационными. Принципы прав человека как основа гендерного равенства и нормы позитивной дискриминации

\footnotetext{
11 Science, engineering, technology.
}

12 Среди документов, легитимизирующих эти структуры и определяющих принципы борьбы с гендерным неравенством, - документы, которые вырабатываются в ООН: Устав ООН, Всеобщая декларация прав человека, а также международные конвенции, одна из которых - «Конвенция о ликвидации всех форм дискриминации в отношении женщин» (1979 г., см.: https:/www.un.org/ru/documents/decl_conv/conventions/cedaw.shtml). Эта конвенция декларирует, что «установление нового международного экономического порядка, основанного на равенстве и справедливости, будет значительно способствовать обеспечению равенства между мужчинами и женщинами».

13 Конвенция ООН «О ликвидации всех форм дискриминации в отношении женщин». Ч. 1. СТ. 4, п. 1. 
закрепляются прежде всего применительно к сфере занятости. Эксперты признают наибольшую законодательную урегулированность гендерного равенства в социальной политике Европейского союза [Тарусина, Исаева 2013 с. 56-58].

Занятость в науке - одна из центральных, где эти вопросы активно обсуждаются и внедряются на протяжении последних лет. В политику эти принципы в международном масштабе проводятся через комплекс различных программ, направлений, инициатив, неправительственных организаций и т. П. Процесс внедрения принципов гендерного равенства является многослойным. Он направлен на новое качество научных результатов, взаимоотношений исследований и общества и включает различные подходы к установлению гендерного равенства: фиксирование числа женщин в различных сферах науки, инжиниринга; преобразование устройства научно-исследовательских институтов с целью устранения барьеров; влияние на формирование знаний путем включения гендерного анализа в фундаментальные и прикладные исследования (гендерные инновации) [Schiebinger, Schraudne 2011].

Наиболее очевидна деятельность в первом из названных направлений, что связано с необходимостью более эффективного использования женской рабочей силы. В США и Европе усилия в этом направлении, включая поддерживающие карьеру женщин в науке и технологий, начали предприниматься в $1980-$ х гг. ${ }^{14}$ и привели к формированию мер и программ по институциональным изменениям в этой сфере. Среди современных международных программ, включающих проблематику гендерного равенства, известна рамочная программа исследований Европейского союза по развитию научных исследований и технологий «Горизонт». В последней из них - «Горизонт-2020» (2014-2020) - принято решение о внедрении подхода «Ответственные исследования и инновации» (Responsible Research and Innovations $-R R I)^{15}$. Его замысел состоит в создании взаимодействия различных сторон (общественных субъектов), затрагиваемых исследовательско-инновационным процессом (исследователи, граждане, политики, бизнес, организации третьего сектора и т. д.), на принципах, максимально широко учитывающих подходы к справедливости. Фокусом является оценка потенциальных последствий и ожиданий общества в отношении исследований и инноваций, необходимых для согласования с ценностями и потребностями общества. С этой целью предусмотрены меры по пяти основным тематическим элементам, среди которых обсуждается и гендерная проблематика (остальные обозначены как участие общественности в научных исследованиях и инновациях, облегчение доступа к научным результатам, этика в содержании и процессе научных исследований и инноваций, а также формальное и неформальное научное образование).

Стратегическое направление «Активизация поддержки гендерного равенства в научно-исследовательской и инновационной политике» (гендерное равенство

\footnotetext{
14 В 1989 г. Национальный фонд США создал целевую группу по программам для женщин в целях повышения их конкурентоспособности в научной деятельности. Аналогичные меры рекомендовала Европейская комиссия в докладе 2000 г. Европейской сети по оценке технологий. В то же время усилия в рамках этого подхода критиковались за то, что его применение не позволяет выйти за рамки женской карьеры и рассмотреть необходимость реформирования институциональных условий - научных институтов и методов исследований [Schiebinger, Schraudne 2011, c. 155-156].

15 Принципы и подходы ответственности в исследованиях и инновациях (RRI) в последнее время обсуждаются в России (Тюменский политехнический институт, МГТУ им. Баумана, см., напр.: [Гаврилина, Казакова 2019]).
} 
в научной карьере, гендерная сбалансированность в процессе принятия решений и учет гендерных аспектов в содержании исследований) имеет целью укрепление гендерного баланса в (1) научно-исследовательских группах; (2) процессе принятия решений; (3) содержании исследований и инноваций для повышения научного качества и социальной значимости производимых знаний, технологий и/или инноваций ${ }^{16}$. Первые мониторинговые исследования восприятия RRI среди европейских исследователей показывают определенные позитивные результаты: создание более благоприятной институциональной среды, большую поддержку женщин-исследователей при содействии программ гендерного равенства [Buehrer, Wroblewski 2019].

Среди механизмов внедрения принципов гендерного равенства в сфере науки, инноваций, образования в широкую практику, действующих на международном уровне как общественные инициативы, следует упомянуть такие платформы, как Гендерный саммит (Gender summit), созданный некоммерческой организацией Portia $^{17}$, и Женский форум (Women's forum for the Economy \& Society), кооперирующийся со многими международными компаниями ${ }^{18}$. На этих платформах проходит обсуждение проблем, инициатив и мер политики в сфере $\mathrm{STEM}^{19}$, связанных с гендерным неравенством.

При участии Гендерного саммита, стартовавшего в 2011 г., в программу ЕС «Горизонт-2020» были внесены две темы - гендерная проблематика и механизмы признания гендерного фактора как измерения качества в этой сфере, в т. ч. на основе учета большего гендерного равенства за счет увеличения числа женщин в науке; интегрированного включения гендерного анализа в исследовательский процесс; поощрения исследований, учитывающих гендерную проблематику. Женский форум, начавший работу в 2009 г., рассматривает инициативы в области STEM в более широком спектре вопросов.

Институциональные механизмы и программы гендерного равенства в сфере образования, науки, инноваций формируются на уровне национальных правительств многих стран [Мальшиева 2012; Шведова 2015]. Интерес представляет сравнение инновационных систем, инициатив в области гендерного равенства в странах Европы для выработки мер по обеспечению гендерного равенства в сфере НИОКР, учитывающих сложности и разнообразие контекстов [Palmén et al. 2019].

В основных правительственных программах, принятых в последние годы в России, вопросы гендерного равенства не развиваются ${ }^{20}$ : документы ограничиваются общими тезисами о недоиспользовании потенциала женщин в инновационном развитии и необходимости роста зарплат ${ }^{21}$. В проектах научно-технического развития гендерные аспекты также не затрагивались, основной социальной

\footnotetext{
16 Responsible \&esearch \& Innovation // European Commission // https:/ec.europa.eu/programmes/horizon2020/en/h2020-section/responsible-research-innovation

17 https://gender-summit.com

18 http://www.womens-forum.com

19 Science, Technology, Engineering and Mathematics.

20 Отметим это как очевидно продолжающуюся тенденцию: так, законотворческая и политическая деятельность в сфере гендерного равенства в целом была довольно активная в 1990-2000-е гг, но не дала больших прорывов в этом отношении в общественном и политическом климате [Айвазова 2003; Воронина 2013].

21 Национальная стратегия действий в интересах женщин на 2017-2022 гг; утверждена распоряжением Правительства Российской Федерации от 8 марта 2017 г. № 410-р.
} 
группой, относительно которой обсуждались приоритеты национальной политики, была молодежь ${ }^{22}$. Государственная программа Российской Федерации «Научно-технологическое развитие Российской Федерации» на 2018-2025 гг. также не включает отдельных направлений или программ, посвященных гендерному неравенству.

Определенная гендерная индифферентность в отношении научной сферы на уровне российской национальной научно-технической политики связана со многими обстоятельствами и прежде всего с историей вопроса, т. е. с более высоким уровнем занятости женщин в естественных и технических науках, в т. ч. в результате того, что принципы гендерного равенства в этой сфере, как и занятости в целом, были провозглашены на уровне государства существенно раньше, чем в европейских странах [Тарусина, Исаева 2013]. Другая причина относится, как уже упоминалось выше, к кризису в области науки, который так или иначе коснулся всех научных работников, и женщин, и мужчин, разрушив прежние институциональные механизмы формирования статуса ученого и не создав при этом новых и адекватных. Есть и иные аспекты сложившейся ситуации, которые могут стать предметом исследований, многие из них относятся, скорее, к политической игре, негативной реакции на определенные политические несбалансированные решения, что, в общем, тоже можно рассматривать как часть международного спектра мнений по этому поводу. Гендерные проблемы в науке обсуждаются в сообществе, но эта дискуссия носит, скорее, локальный характер ${ }^{23}$ и не имеет большого резонанса.

\section{Социальные программы гендерного равенства в биографическом опыте ученых}

Обратимся более подробно к анализу случаев, способствовавших перемещению внимания исследования к вопросам влияния социальных программ гендерного равенства в науке с точки зрения профессионального развития, о которых было упомянуто в начале статьи. Эти вопросы были подняты в первых же биографических интервью исследователей-женщин, работавших или работающих в настоящее время за рубежом. Их можно обсуждать в свете проблемы неосознаваемости (невоспринимаемости) проявления гендерного неравенства в повседневной практике, которая становится очевидной в соотнесении с опытом работы в других условиях, со взглядом «со стороны». Иными словами, объектом внимания становятся неосознаваемые (незамечаемые) слабые стороны положения женщин в науке, а также способы предоставления возможностей их осознания и объективной оценки.

\footnotetext{
22 Стратегия научно-технологического развития Российской Федерации; утверждена Указом Президента Российской Федерации от 1 декабря 2016 г. № 642.

23 В дискуссии на сайте «Постнаука» общим для экспертов стало более или менее явно выраженное согласие с тем, что гендерное неравенство не является важной проблемой российской науки (см.: Точка зрения. Сексизм в науке (2014) // ПостНаука. 4 июня 2014 // https://postnauka.ru/talks/26589). Разнообразны и сбалансированы аргументы за и против гендерного равенства в серии обсуждений «W-Science: женщины в науке» (см.: https://laba.media/courses/w-science-zhenshchiny-v-nauke).
} 
Я остановлюсь лишь на некоторых эпизодах из биографических интервью, позволяющих выделить основные аспекты этой проблемы.

Выборка исследования формировалась в соответствии с критериями пола, возраста, работы в России и за рубежом (в Австралии, Бельгии, Великобритании, Канаде, Латвии, Мексике, Новой Зеландии, США, Швеции и др.). При опросе выдерживались равные пропорции по полу в возрастных группах до 40, от 40 до 60 и старше 60 лет, а также по месту занятости на момент интервью в российском или зарубежном исследовательском институте. Респонденты подбирались целенаправленно и с использованием метода «снежного кома». В числе основных критериев обязательным было наличие научной степени. Интервью с учеными, живущими за рубежом и в некоторых российских городах, проводились по скайпу.

В исследовании применялись принципы методологии биографическо-нарративного полуструктурированного интервью [Wengraf 2001]: первая его часть была посвящена рассказу о профессиональной биографии с минимальным участием интервьюера, вторая заключалась в ответах на уточняющие вопросы относительно обстоятельств, формирующих этот путь, сохраняя при этом важность индивидуальной оценки. Продолжительность интервью в среднем составляла около двух часов. Как уже отмечалось, вопросы, выделяющие гендерные аспекты профессионального пути, первоначально не планировались, но после первых же интервью, в которых они неожиданно возникли, эти вопросы были включены в тематику разговора о профессиональной карьере. Таким образом, тема гендерных программ и инициатив в научной политике выделилась фактически спонтанно и в дальнейшем включалась в вопросы интервью его структурированной части (т. е. не во все интервью).

В анализе, фокусирующемся на этой теме, выбирались законченные смысловые фрагменты интервью, в которых интервьюеры говорили об опыте осознания влияния гендерных программ / политики гендерного равенства в своей профессиональной деятельности за рубежом ${ }^{24}$. Его целью была оценка степени и потенциала осознания в научном сообществе гендерных аспектов профессиональной деятельности через анализ специфики их восприятия учеными, которые в той или иной степени испытали влияние программ гендерного равенства и выделяли этот опыт как важный для осмысления своего положения и перспектив его развития.

\section{Противоречия в трудоустройстве}

В своих интервью ученые рассказывали о ситуациях в сфере занятости, в т. ч. произошедших давно, останавливаясь на событиях, которые заставили их по-новому оценивать эти случаи и связанные с ними контексты. Так, проблему гендерного равенства в научной деятельности подняла исследовательница, работающая в настоящее время в Великобритании: участие в семинаре по вопросам гендерного равенства на новом месте работы в этой стране заставило ее переосмыслить

\footnotetext{
24 Одновременно в целях сравнения отбирались фрагменты интервью, в которых респонденты описывали опыт, который можно отнести к практикам дискриминации по гендерному признаку в повседневной жизни вне зависимости от оценки респондента и его осознания с учетом программ / политики гендерного равенства.
} 
собственный опыт гендерной дискриминации при послевузовском трудоустройстве в родном городе. «После университета $<\ldots>$ в этот год [в первый год после окончания вуза] в самом лучшем научно-исследовательском институте города директор решил женщин не брать вообще. <...> Я такие вещии как-то вытесняла из своего сознания, но недавно пришлось вспомнить именно потому, что здесь [в университете в Великобритании] с женщинами занимаются и активно им помогают. Тут была программа для женщин, <...> они просили вспомнить случаи какой-то дискриминачии, и я говорю: “Да нет никакой дискриминации”, а потом я стала вспоминать: “Да, батюшки святы, меня же даже на работу не взяли тогда!”” (физик-теоретик, ж., 50 лет, Великобритания).

Важно было понять, что спровоцировало возникновение этой ситуации: было ли это единичное, персональное решение директора института, убежденного в «нерентабельности» женщин в институте (из-за возможного ухода в декрет: «Ну их, этих женщин, потом они все уйдут в декрет»), или важнее то, что общая атмосфера в таких институтах в принципе позволяла допустить и оставить в силе подобные решения руководства. Следует отметить, что в данном случае мнение общественности все-таки стало основным сдерживающим фактором начальственного своеволия: директора, по словам респондентки, удалось переубедить, и в следующем году он свое решение отменил. «Ученому совету это не понравилось. Они решили: "Что мы тут мужским монастырем, что ли, будем работать?”. И они цельий год этого директора обрабатывали: “Ну да, они [женщины] уйдут в декрет, но потом они вернутся и будут пахать. И в отличие от мужиков, которые более мобильны и могут в любой момент слинять, они как раз наоборот будут показывать, что работают хорошо". Ну и вот, только через год меня взяли в институт» (физик-теоретик, ж., 50 лет, Великобритания).

\section{Распределение ролей в коллективе}

Рефлексия по поводу справедливости в распределении ролей и шансов профессионального развития на рабочих местах в исследовательских коллективах происходит под влиянием различных обстоятельств. Важны не только лекции, побуждающие выявлять способы дискриминации, но и сравнение климата в коллективах в различных институтах за рубежом и в России, позволявшее на этом основании осмысливать несправедливость устоявшихся гендерных стереотипов и норм в повседневном обращении и профессиональном продвижении. В то же время очевидно и то, что оценивать эти различия помогает определенное гендерное просветительство. По мнению респондентки, имевшей опыт работы за рубежом, ее позиция сформировалась в немалой степени на основе знакомства с гендерными исследованиями при личном общении с социологами, занимающимися ими. Это помогло более четко формулировать свою позицию: «Бороться [за направление в науке] приходится на каждом этапе. И тут, мне кажется, часто становится гендерный вопрос. <... Ч Что интересно, в России, мне кажется, он стоит гораздо более остро, чем за рубежом. Все знакомые, кому я об этом рассказываю, удивляются. А такая проблема есть, и она стоит остро. Это очень заметно, когда приезжаешь [из-за рубежа (речь идет о Великобритании)]. Там нет такого, а здесь буквально на каж- 
дом шагу» (физик, ж., 30 лет, Россия). В этом рассказе выявляются две проблемы, одна из которых - культура взаимоотношений в коллективе, признающая «<... шутки некоторой сексистской направленности. <...> Они [мужчины в коллективе в российском институте] себе такие вещзи позволяют, о которых я уже много лет не сльшила. < ..> Такая, казалось бы, безобидная вещзь, но в [университете в Великобритании] никто себе такого не позволял» (физик, ж., 30 лет, Россия).

Другая проблема - неявные в повседневном рабочем режиме нормативные предписания для женщин, формально равных по статусу со своими коллегамимужчинами, которые предполагают для них преимущественно исполнительские функции. «Ситуация такая, что взяли одновременно меня постдоком и еще одного парня, у которого похожая ситуация - он только что закончил PhD [за рубежом]. И его как-то стимулируют <..> на гранты подавать. Его приняли гораздо проще, чем меня. Да просто даже потому, что коллектив, в общем-то, мужской. И [про то, что нужно на] какие-то собрания постдоков ходить, я косвенно совершенно узнаю от него же. <..> Его явно информируют больше по какимто вопросам, которые мне тоже интересны, а меня, считают <... $>$, не надо [информировать]» (физик, ж., 30 лет, Россия). Это распространенная характеристика скрытого, неформального распределения ролей в коллективе института в целом: «<..> Прозвучала такая фраза, что у руководителя лаборатории, с которым я пока не знакома, женщины в основном - это административный персонал. И, как я поняла, это не только здесь. От других тоже сльшала комментарии, что часто случается так, что женщзины более склонны к тому, чтобы соглашаться на какую-то бумажно-административную работу, берут на себя во многом административную ношу. Здесь, конечно, это очень серьезный гендерный вопрос. В [университете в Великобритании, на прежнем рабочем месте] этого не было» (физик, ж., 30 лет, Россия). В то же время именно видение этих гендерных аспектов профессиональной деятельности приводит к пониманию своей позиции: «<..> Я думаю, что все это в приничие преодолимо. Сейчас у меня действительно прорезался голос, потому что я посмотрела на совершенно другую картину и поняла, что это ненормально, так не должно быть, а раньше считала, что я просто хуже» (физик, ж., 30 лет, Россия).

Эти осознаваемые благодаря широким дискуссиям различия подтверждают другие исследователи, работающие (или работавшие) за рубежом. На это, например, указывает довольно взвешенное и нейтрально окрашенное замечание: $«<\ldots>$ Отношение к роли женшины в науке у нас и на Западе различное. До недавнего времени я не думала, что это является проблемой, пока не возник скандал с Алессандро Струмиа ${ }^{25}$ в ЦЕРНе. Возможно, это новое явление, от которого нельзя так просто отмахнуться» (физик, ж., 49 лет, Россия; имеет опыт работы в Италии).

Осторожность в отношении оценки меры справедливости таких практик заметна в других рассказах. Такая же сдержанность, например, есть в рассказе

\footnotetext{
25 Речь идет об обстоятельствах увольнения итальянского физика А. Струмиа из-за выступления на семинаре ЦЕРНа по теории высоких энергий и гендеру, где он заявил, что, согласно проведенному им анализу, в академических кругах физики существует гендерная предвзятость в отношении женщин и дискриминация в отношении мужчин-ученых. Наиболее известны и скандальны его высказывания о том, что «физику придумали и построили мужчины», и что «в нее не приглашают», говоря о преференциях для физиков-женщин. ЦЕРН отстранил его от должности «приглашенного ученого» из-за нарушения этического кодекса поведения, что вызвало споры в научном сообществе по поводу обоснованности и справедливости такого решения.
} 
респондентки из Австралии: «<...> Здесь очень сильно продвигается сейчас Women in Science u gender policy <...>. Наверное, даже больше, чем надо на самом деле. < ...> Должно быть одинаковое количество мужчин и женщин. Если у тебя два кандидата, одинаково сильных (мужчина и женщина), то ты должен отдавать предпочтение женщиине. <... Для меня это немножко странно, потому что девяносто пять процентов окружения - мужчины <..., и для меня это норма. Я привыкла к этому. < .. > Напор в другую сторону меня немножко удивляет, скажем так. Но, с другой стороны, я понимаю, что это очень круто. < ... $>$ Здесь, в Австралии, на этом становятся все больше и больше помешаны. То есть, буквально, это моя работа каждый день. Здесь есть отдельная организаиия, Wотеп in Physics, <...> которая очень все сильно это продвигает» (биофизик, ж., 40 лет, Австралия).

Что касается идеализированных представлений об иной, более справедливой к коллегам-женщинам, культуры отношений в исследовательских коллективах за рубежом под влиянием соответствующей политики, то свидетельства возможной иллюзорности более справедливого гендерного климата встречаются, например, в рассказах мужчин-исследователей: «Я мог бы сказать, что, как мне кажется, на Западе кое-где есть довольно серьезные проблемы в смысле недоброго отношения к женскому полу. Я несколько раз с этим сталкивался. < .. > Когда коллеги, совершенно нормальные люди мужского пола, в какой-то момент [разговора возражали], оказывалось, что "ты, вообще, о чем говоришь? Она же женщина". Мне в России никто так не говорил. <... Р Поскольку за это бьют [на Западе], то это не очень стараются показывать. И молодые аспирантки, как правило, этого не замечают. И дай бог, чтобы это реально не аукнулось в какой-то момент» (биофизик, м., 48 лет, Бельгия).

\section{Сочетание профессиональных и семейных ролей}

Наиболее серьезная объективная трудность в профессиональном продвижении женщин, как известно, связана с необходимостью сочетать профессиональную деятельность с воспитанием детей. В оценке этих сложностей практически нет различий, их преодоление требует сосредоточения всех сил: «Есть момент, такой, женский, семейный, -уход в декрет: как потом восстановиться, как не потерять темп» (физик, ж., 29 лет, Россия). В исследовательских институтах этот вопрос иногда решается благодаря введению свободного режима и возможности работать дистанционно: «Тут у нас есть опять же плюс в том, что достаточно вольный режим, < ..> многие работают из дома» (физик, ж., 29 лет, Россия).

Весьма актуальны эти проблемы и за рубежом. «У меня есть положительные примеры: [коллега], которая сейчас [работает за рубежом] постдоком, у нее маленький ребенок. <..> Конечно, достаточно сложно, но она балансирует. Ей пришлось сидеть [дома] порядка года, но еще до года она отдала ребенка в детский сад. Конечно, ей приходится очень четко планировать свой рабочий день, потому что в пять часов его нужно уже забрать. Но она молодеи, она умудряется все сбалансировать» (физик, ж., 30 лет, Россия). При этом в биографиях работающих за рубежом российских ученых, которые стали там родителями 
(немногочисленные случаи в выборке), отмечается благоприятствующая этому важному шагу общественная атмосфера, которая делает его осознанным: «<..> Законы [в Швеции] к родителям благосклонны и в плане трудового законодательства, и в плане медицинских вещчей, все очень устроено для родителей, и мы поняли, что если мы хотим завести ребенка, то лучшего момента для этого нет» (биофизик, м., 32 года, Швеция).

В рассказах о российской повседневности отмечаются случаи несправедливого отношения, касающегося возможности сочетания профессиональных и семейных обязанностей в трудный период рождения и воспитания ребенка, которые совершенно не принимаются во внимание действующей практикой трудовых контрактов, трудоустройства и профессионального развития. Но это звучит скорее как констатация, а не как осознанная и целенаправленная критика явного факта гендерной несправедливости. «Если женщина в отпуске по уходу за ребенком, у нее закончился контракт, она должна выйти на конкурс из отпуска. <...> Но требования к преподавателям в университете таковы, что если она что-то на самом деле не делает, сидя в этом отпуске, и руководитель кафедры не вписал ее в публикации, то она не пройдет конкурс по публикациям. <...> То есть формально все по кодексу: срочный контракт закончен - до свиданья. Не придерешься юридически, но с человеческой точки зрения это очень жесткий способ» (биолог, ж., 32 года, Россия). В таком же ключе упоминались случаи препятствий в продолжении научной профессиональной карьеры на том основании, что материнство в нее «не вписывается». Один из них является фактическим отказом поддержать работу над диссертацией молодой сотрудницы института в связи с рождением второго ребенка: «Я $8 b l-$ ила на предзашиту, а моя руководительница [во время обсуждения] сказала, что она против того, чтобы я защчищалась, потому что у меня на уме только дети. <...> Она сказала: “Пускай она занимается детьми”" (биолог, ж., 36 лет, Россия).

Исследование, первоначально не ориентированное на подробный анализ гендерных аспектов профессиональной карьеры, но впоследствии включившее их в круг значимых тем, не дает материала для более детальной характеристики возможностей и перспектив социальных программ гендерного равенства в науке. Анализ интервью показывает, что осознание комплекса гендерных проблем в профессиональной деятельности связано со средой, которая формирует более обоснованное отношение к ним. Именно это определяет степень, в которой проблемы гендерного равенства становятся заметными, осознанными в собственной профессиональной карьере, отношение к различным способам их решения их обоснованности, справедливости, актуальности и соответствия реальному состоянию дел в научной среде.

\section{Выводы}

Гендерное равенство в сфере науки и технологий может рассматриваться как базовый политический принцип в более эффективном использовании ресурса женской занятости, в т. ч. через возможности профессионального развития и механизмы формирования карьеры. В свою очередь, профессиональная карьера в науке зависит от ресурсов, которые формируются преимущественно в государственной 
научной политике и учитывают необходимость смягчения дискриминирующих практик. Их создание происходит на различных уровнях, и общий фон задает международный уровень - через законодательство, программы и инициативы, которые в свою очередь способствуют созданию институциональных механизмов на уровне национальных политик. Сфера науки и технологий - международная сфера профессиональной деятельности, но существуют особенности политики, стереотипов и норм: так, в России вопросы гендерного равенства не выходят на передний план в силу различных причин, среди которых - кризисное состояние науки в целом: трудности в профессиональном развитии относятся, скорее, ко всей социопрофессиональной группе ученых и ее статусу в обществе. Можно предположить, что институциональная поддержка гендерного равенства будет восприниматься гораздо органичнее и позитивнее на фоне поддержки статуса и перспектив российской науки в целом. Эти процессы должны быть взаимосвязаны и сбалансированы, тем более что в России борьба с гендерным неравенством в сфере науки имеет более длительную историю, чем, например, на Западе, где сейчас задается модус современных подходов и программ гендерного равенства.

На это указывает то, что проявления гендерного неравенства во многих ситуациях занятости в российских исследовательских институтах и университетах, попавших в фокус эмпирического исследования, практически не замечаются теми, кто в такие ситуации попадает. В тех же случаях, когда профессиональная биография ученого включает опыт работы за рубежом, эти проблемы осознаются, вырабатываются определенные (индивидуальные) способы их решения. И в этом (осознании и формулировании проблем гендерного неравенства в профессиональном развитии) очевидна позитивная сторона социальных программ, влияющих на карьерные стратегии в международном масштабе. За скобками историй остается возможный негативный аспект - образование новых источников дискриминации и гендерных неравенств, формальность многих применяемых критериев к их проявлениям и «внутренний сексизм».

Дискуссионными остаются вопросы возможностей, которые определяются социальной политикой, включающей принципы, подходы и программы гендерного равенства, в т. ч. применительно к ситуации в российской науке. Согласие может быть достигнуто в следующем: проблема гендерного равенства в научной карьере может успешно решаться благодаря формированию научной среды, регулируемой инструментами научной политики, включая сбалансированную поддержку изменений в организации научно-исследовательских учреждений и в содержании научно-исследовательской деятельности. Чтобы понимать их реальную эффективность, необходимо проведение широких дискуссий по поводу дискриминирующих практик в организации профессионального развития не только женщин, но и мужчин, в т. ч. как возможных следствий соответствующих программ.

\section{Литература}

Агамова Н.С., Аллахвердян А.Г. (2000) Российские женщины в науке и высшей школе: историко-научные и науковедческие аспекты. К 150 -летию со дня рождения С.В. Ковалевской // Вопросы истории и естествознания. № 1. С. 17-23. 
Айвазова С.Г. (2003) Гендерное равенство как проблема российских реформ // Заславская Т.И. (ред.) Куда пришла Россия? Итоги социетальной трансформации. Международный симпозиум. С. 131-140.

Богданова И.Ф. (2004) Женщины в науке: вчера, сегодня, завтра // Социологические исследования. № 1. С. 103-111.

Воронина О.А. (ред.) (2008) Гендерное равенство в современном мире: роль национальных механизмов. М.: МАКС Пресс.

Воронина О.А. (2013) Политика гендерного равенства в современной России: проблемы и противоречия // Женщина в российском обществе. № 3(68). С. 12-20.

Гаврилина Е.А., Казакова А.А. (2019) Социальная оценка техники и технологий: перспективы направления // Социологические исследования. № 12. С. 143-145.

Гнедаш А.А. (2016) Национальный механизм гендерного равенства в современной России и странах мира: акторы, глобальный и локальный уровни, сетевые ресурсы // Женщина в российском обществе. № 4(81). С. 1-20.

Грицай Л.А. (2011) Материнство и наука: к вопросу о родительских установках современных российских женщин-ученых // Социология науки и технологий. Т. 2. № 4. С. 99-104.

Долгова Е.А., Стрельцова Е.А. (2019) «Добро пожаловать в клуб»: положение женщин в советской науке 1920-х годов // Социологические исследования. № 2. С. 97-107.

Женщины и мужчины России-2018 (2018) Стат.сб. М.: Росстат.

Здравомыслова Е.А., Темкина А.А. (2015) 12 лекций по гендерной социологии: учебное пособие. СПб.: Изд-во Европейского университета в Санкт-Петербурге.

Канарш Г.Ю. (2019) Социальная справедливость: современная история идеи // Горизонты гуманитарного знания. № 1. С. 48-73.

Келле В.Ж., Кугель С.А. (ред.) (1991) Научные кадры СССР: динамика и структура. М.: Мысль.

Малышева M.M. (2016) Естественные и технические науки для женщин в XXI веке // Народонаселение. № 3(73). С. 76-85.

Попова И.П. (2016) Воспроизводство профессиональной группы научных работников: проблемы устойчивости и неравенств // Мансуров В.А. (ред.) Социология и общество: социальное неравенство и социальная справедливость. Материалы V Bсероссийского социологического конгресса. М.: РОС. С. 6486-6496.

Попова И.П. (2017) Профессиональная карьера в сфере науки и технологий - к проблеме устойчивости // Социологические исследования. № 12. С. 124-134. DOI: $10.7868 / \mathrm{S} 0132162517120133$

Пушкарева Н.Л. (2017) Смешны ученые девицы? (Проблема стигматизации женщин-ученых и влияние социальных ожиданий на женские жизненные стратегии и стиль жизни) // Вопросы истории естествознания и техники. Т. 38. № 4. С. 756-770.

Рождественская Е.Ю. (2019) Академическая женская карьера: балансы и дисбалансы жизни и труда // Мониторинг общественного мнения: Экономические и социальные перемены. № 3. С. 27-47.

Рощин С.Ю., Зубаревич Н.В. (2005) Гендерное равенство и расширение прав и возможностей женщин в контексте целей развития тысячелетия. М.: Информационный центр ООН ПРООН.

Тарусина Н.Н., Исаева Е.А. (2013) Гендер: нейтрализация и позитивная дискриминация: учебное пособие. Ярославль: ЯрГУ.

Труд и занятость в России-2019 (2019). Стат.сб. М.: Росстат.

Черныш М.Ф. (2020) Концептуальные основы социальной политики: достоинство, справедливость, равенство // Социологический журнал. Т. 26. № 1. С. 8-30. DOI: 10.19181/socjour.2020.26.1.7051

Шведова Н.А. (2015) Развитие человеческого капитала и гендерное равенство: умная гендерная политика // Женщина в российском обществе. № 3/4 (76/77). С. 17-30.

Штомпка П. (2017) Справедливость // Мониторинг общественного мнения. № 6. С. 381-399. Хьюэр С. (2015) Сокращается ли гендерное неравенство в области науки и техники? // UNESCO Science Report: Towards 2030. C. 85-103.

Andresen M., Apospori E., Gunz H. et al. (2020) Careers in Context: An International Study of Career Goals as Mesostructure between Societies' Career-Related Human Potential 
and Proactive Career Behaviour // Human Resource Management Journal, vol. 30, pp. 365-391. DOI: 10.1111/1748-8583.12247

Blickenstaff J.C. (2005) Women and Science Careers: Leaky Pipeline or Gender Filter? // Gender and Education, vol. 17, no 4, pp. 369-386.

Buehrer S., Wroblewski A. (2019) The Practice and Perceptions of RRI-A Gender Perspective // Evaluation and Program Planning, vol. 77. DOI: 10.1016/j.evalprogplan.2019.101717

Cuzzocrea V., Lyon D. (2011) Sociological Conceptualisations of 'Career': A Review and Reorientation // Sociology Compass, vol. 5, no 12, pp. 1029-1043. DOI: $10.1111 /$ j. 1751-9020.2011.00429.x

Devine F. (1992) Gender Segregation in the Engineering and Science Professions - A Case of Continuity and Change // Work Employment and Society, vol. 6, no 4, pp. 557-575.

Duberley J., Cohen L., Mallon M. (2006) Constructing Scientific Careers: Change, Continuity and Context // Organization Studies, vol. 27, no 8, pp. 1131-1151.

Dubois-Shaik F., Fusulier B. (eds.) (2015) Academic Careers and Gender Inequality: Leaky Pipeline and Interrelated Phenomena in Seven European Countries // Garcia. Working Paper. No. 5 // https://eige.europa.eu/sites/default/files/garcia_working_paper_5_academic_ careers gender inequality.pdf

Dulini F., Cohen L., Duberley J. (2019) Navigating Sexualised Visibility: A Study of British Women Engineers // Journal of Vocational Behavior, vol. 113, pp. 6-19.

Ecklund E.H., Lincoln A.E., Tansey C. (2012) Gender Segregation in Elite Academic Science // Gender \& Society, vol. 26, no 5, pp. 693-717.

Hobson B. (2018) Gendered Dimensions and Capabilities: Opportunities, Dilemmas and Challenges // Critical Sociology, vol. 44, no 6, pp. 883-898.

Kameshwara K.K., Shukla T. (2017) Towards Social Justice in Institutions of Higher Learning: Addressing Gender Inequality in Science \& Technology through Capability Approach // Administrative Sciences, vol. 7, no 3. DOI: 10.3390/admsci7030022

Lawrence B.S. (2011) Careers, Social Context and Interdisciplinary Thinking // Human Relations, vol. 64 , no 1 , pp. 59-84. DOI: $10.1177 / 0018726710384293$

Mann A., DiPrete T.A. (2013) Trends in Gender Segregation in the Choice of Science and Engineering Majors // Social Science Research, vol. 42, no 6, pp. 1519-1541.

Nussbaum M.C. (2003) Capabilities as Fundamental Entitlements: Sen and Social Justice // Feminist Economics, vol. 9, no 2-3, pp. 33-59.

Nussbaum M.C. (2016) Women's Progress and Women's Human Rights // Human Rights Quarterly, vol. 38, no 3, pp. 589-622.

Palmén R., Kalpazidou Schmidt E., Striebing C., Reidl S., Bührer S., Groóf D. (2019) Measuring Gender in R\&I - Theories, Methods, and Experience // Interdisciplinary Science Reviews, vol. 44, no 2, pp. 154-165.

Rhoads R.A., Gu D.Y. (2012) A Gendered Point of View on the Challenges of Women Academics in the People's Republic of China // Higher Education, vol. 63, no 6, pp. 733-750.

Robeyns I. (2003) Sen's Capability Approach and Gender Inequality: Selecting Relevant Capabilities // Feminist Economics, vol. 9, no 2-3, pp. 61-92.

Sagebiel F. (2014) Academic Women Leaders' Career and Their Potential as Gendered Organizational Change Agents // (Re)searching Scientific Careers (eds. Prpić K., van der Weijden I., Asheulova N.), Saint Petersburg: Nestor-Historia, pp. 85-114.

Schiebinger L., Schraudne M. (2011) Interdisciplinary Approaches to Achieving Gendered Innovations in Science, Medicine, and Engineering // Interdisciplinary Science Reviews, vol. 36, no 2, pp. 154-167.

Sen A. (1995) Gender Inequality and Theories of Justice // Women, Culture and Development: A Study of Human Capabilities, New York: Oxford University Press Inc., pp. 259-273.

Wengraf T. (2001) Qualitative Research Interviewing: Biographic Narrative and Semistructured Methods, Sage: Thousand Oaks.

Xie Yu, Shauman K.A. (2003) Women in Science: Career Processes and Outcomes, Harvard University Press. 


\title{
Gender Equality in Science and Technology as a Factor in Professional Careers ${ }^{26}$
}

\section{POPOVA*}

\begin{abstract}
*Irina Popova - PhD in Sociology, Leading Researcher, Institute of Sociology of the Russian Academy of Sciences (ISRAS). Address: bld. 5, 24/35, Krzhizhanovskogo St., Moscow, 117218, Russian Federation. E-mail: irina_popova@list.ru

Citation: Popova I. (2021) Gender Equality in Science and Technology as a Factor in Professional Careers. Mir Rossii, vol. 30, no 2, pp. 98-122 (in Russian). DOI: 10.17323/1811-038X-2021-30-2-98-122
\end{abstract}

\begin{abstract}
The characteristics of professional careers in the field of science and technology are examined here from the viewpoint of gender equality and justice in employment. Our analysis of career research in this field is based on approaches that focus on the structural conditions and contexts of career formation (here we analyze the data up to March 2020). Modern programs and initiatives in science and technology recognizing gender equality in professional careers at national and international levels are becoming one of the factors of these conditions. In this context, approaches that justify gender equity (the capabilities approach), and issues of positive discrimination in relation to employment and professional advancement in this area are utilized. We analyze the aspects of managing a scientific career, which, in the biographical narratives of scientists, are recognized and reconsidered as manifestations of gender inequality in the experience of familiarization with programs within the policy of gender equality in scientific activity. The analysis is based on narrative-biographical semi-structured interviews with scientists in the field of natural sciences ( $\mathrm{N}=40,2018-2019)$. Assessments of the manifestations of gender inequality pertain to employment, role distribution within a team in accordance with informal norms, and the balancing of professional and family roles. We conclude that with regard to gender inequality in employment in the science, the manifestations of which often go unnoticed, creating opportunities for their examination and assessment by the scientists themselves is relevant and should be regulated by scientific policy instruments. Institutional support for gender equality should happen in conjunction with support for the status and prospects of Russian science in general.
\end{abstract}

Keywords: professional career, career studies, justice, gender equality, science and technology, positive discrimination, science policy

26 The paper was prepared with the financial support of the Russian Foundation for Basic Research (RFBR), project No. 19-511-93003. 


\section{References}

Agamova N. S., Allahverdyan A. G. (2000) Rossijskie zhenshchiny v nauke i vysshej shkole: istoriko-nauchny i naukovedcheskie aspekty. K 150-letiyu so dnya rozhdeniya S. V. Kovalevskoj [Russian Women in Science and Higher Education: Historical, Scientific and Scientific Aspects. To the 150th Anniversary of the Birth of S.V. Kovalevskaya]. Voprosy istorii i estestvoznaniya, no 1, pp. 17-23.

Ajvazova S.G. (2003) Gendernoe ravenstvo kak problema rossijskih reform [Gender equality as a problem of Russian reforms]. Kuda prishla Rossiya? Itogi sotsietal'noj transformatsii. Mezhdunarodnyj simpozium [Where Did Russia Arrive? Results of Societal Transformation. International Symposium] (ed. Zaslavskaya T.I.), pp. 131-140.

Andresen M., Apospori E., Gunz H. et al. (2020) Careers in Context: An International Study of Career Goals as Mesostructure between Societies' Career-Related Human Potential and Proactive Career Behaviour. Human Resource Management Journal, vol. 30, pp. 365-391. DOI: $10.1111 / 1748-8583.12247$

Blickenstaff J.C. (2005) Women and Science Careers: Leaky Pipeline or Gender Filter? Gender and Education, vol. 17, no 4, pp. 369-386.

Bogdanova I.F. (2004) Zhenshchiny v nauke: vchera, segodnya, zavtra [Women in Science: Yesterday, Today, Tomorrow]. Sotsiologicheskie issledovaniya, no 1, pp. 103-111.

Buehrer S., Wroblewski A. (2019) The Practice and Perceptions of RRI-A Gender Perspective. Evaluation and Program Planning, vol. 77. DOI: 10.1016/j.evalprogplan.2019.101717

Chernysh M.F. (2020) Kontseptual'nye osnovy sotsial'noj politiki: dostoinstvo, spravedlivost', ravenstvo [Conceptual Foundation of Social Policy: Dignity, Justice, Equality]. Sotsiologicheskij zhurnal, vol. 26, no 1, pp. 8-30. DOI: 10.19181/socjour.2020.26.1.7051

Cuzzocrea V., Lyon D. (2011) Sociological Conceptualisations of 'Career': A Review and Reorientation. Sociology Compass, vol. 5, no 12, pp. 1029-1043. DOI: $10.1111 /$ j.1751-9020.2011.00429.x

Devine F. (1992) Gender Segregation in the Engineering and Science Professions - A Case of Continuity and Change. Work Employment and Society, vol. 6, no 4, pp. 557-575.

Dolgova E.A., Strel'tsova E.A. (2019) «Dobro pozhalovat' v klub»: polozhenie zhenshchin v sovetskoj nauke 1920-h godov ["Welcome to the Club": Position of Women in Soviet Science in the 1920s]. Sotsiologicheskie issledovaniya, no 2, pp. 97-107.

Duberley J., Cohen L., Mallon M. (2006) Constructing Scientific Careers: Change, Continuity and Context. Organization Studies, vol. 27, no 8, pp. 1131-1151.

Dubois-Shaik F., Fusulier B. (eds.) (2015) Academic Careers and Gender Inequality: Leaky Pipeline and Interrelated Phenomena in Seven European Countries. Garcia. Working Paper No. 5. Available at: https://eige.europa.eu/sites/default/files/garcia_working_paper_5_ academic careers gender inequality.pdf, accessed 20.02.2021.

Dulini F., Cohen L., Duberley J. (2019) Navigating Sexualised Visibility: A Study of British Women Engineers. Journal of Vocational Behavior, vol. 113, pp. 6-19.

Ecklund E.H., Lincoln A.E., Tansey C. (2012) Gender Segregation in Elite Academic Science. Gender \& Society, vol. 26, no 5, pp. 693-717.

Gavrilina E.A., Kazakova A.A. (2019) Sotsial'naya otsenka tekhniki i tekhnologij: perspektivy napravleniya [Current Research in TA/RRI, sociology of technology and engineering in Russia: An Overview]. Sociologicheskie issledovaniya, no 12, pp. 143-145.

Gnedash A.A. (2016) Natsional'nyj mekhanizm gendernogo ravenstva v sovremennoj Rossii i stranakh mira: aktory, global'nyj i lokal'nyj urovni, setevye resursy [National Mechanism of Gender Equality in Modern Russia and Countries of the World: Actors, Global and Local Levels, Network Resources]. Woman in Russian Society, no 4(81), pp. $1-20$.

Gricaj L.A. (2011) Materinstvo i nauka: k voprosu o roditel'skih ustanovkah sovremennyh rossijskih zhenshchin-uchenyh [Motherhood and Science: On the Issue of Parental Attitudes of Modern Russian Women Scientists]. Sociology of Science and Technology, vol. 2, no 4, pp. 99-104. 
Huyer S. (2015) Sokrashchaetsya li gendernoe neravenstvo v oblasti nauki i tekhniki? [Is Gender Inequality in Science and Technology Decreasing?]. UNESCO Science Report: Towards 2030, pp. 85-103.

Hobson B. (2018) Gendered Dimensions and Capabilities: Opportunities, Dilemmas and Challenges. Critical Sociology, vol. 44, no 6, pp. 883-898.

Kameshwara K.K., Shukla T. (2017) Towards Social Justice in Institutions of Higher Learning: Addressing Gender Inequality in Science \& Technology through Capability Approach. Administrative Sciences, vol. 7, no 3. DOI: 10.3390/admsci7030022

Kanarsh G.Yu. (2018) Social'naya spravedlivost': sovremennaya istoriya idei [Social Justice: Modern History of the Idea]. Horizons of Humanitarian Knowledge, no 1, pp. 48-73.

Kelle V.Zh., Kugel' S.A. (eds.) (1991) Nauchnye kadry SSSR: dinamika i struktura [Scientific Personnel of the USSR: Dynamics and Structure], Moscow: Mysl'.

Lawrence B.S. (2011) Careers, Social Context and Interdisciplinary Thinking. Human Relations, vol. 64, no 1, pp. 59-84. DOI: 10.1177/0018726710384293

Malysheva M.M. (2016) Estestvennye i tekhnicheskie nauki dlya zhenshchin v XXI veke [Natural and Technical Sciences for Women in the Twenty-first Century]. Population, no 3(73), pp. 76-85.

Mann A., DiPrete T.A. (2013) Trends in Gender Segregation in the Choice of Science and Engineering Majors. Social Science Research, vol. 42, no 6, pp. 1519-1541.

Nussbaum M.C. (2003) Capabilities as Fundamental Entitlements: Sen and Social Justice. Feminist Economics, vol. 9, no 2-3, pp. 33-59.

Nussbaum M.C. (2016) Women's Progress and Women's Human Rights. Human Rights Quarterly, vol. 38, no 3, pp. 589-622.

Palmén R., Kalpazidou Schmidt E., Striebing C., Reidl S., Bührer S., Groóf D. (2019) Measuring Gender in R\&I - Theories, Methods, and Experience. Interdisciplinary Science Reviews, vol. 44, no 2, pp. 154-165.

Popova I.P. (2016) Vosproizvodstvo professional'noj gruppy nauchnyh rabotnikov: problemy ustojchivosti i neravenstv [Reproduction of a Professional Group of Researchers: Problems of Sustainability and Inequality]. Sotsiologiya $i$ obshchestvo: social'noe neravenstvo $i$ social'naya spravedlivost'. Materialy V Vserossijskogo sociologicheskogo kongressa [Sociology and Society: Social Inequality and Social Justice. Materials of the V All-Russian Sociological Congress] (ed. Mansurov V.A.), Moscow: ROS, pp. 6486-6496.

Popova I.P. (2017) Professional'naya kar'era v sfere nauki i tekhnologij - k probleme ustojchivosti [Professional Career in Science and Technology: On Sustainability Problem]. Sotsiologicheskie issledovaniya, no 12, pp. 124-134. DOI: 10.7868/S0132162517120133

Pushkareva N.L. (2017) Smeshny uchenye devicy? (Problema stigmatizacii zhenshchin-uchenyh i vliyanie social'nyh ozhidanij na zhenskie zhiznennye strategii i stil' zhizni) [Are Science Girls Funny? (The Problem of Stigmatization of Women Scientists and the Impact of Social Expectations on Women's Life Strategies and Lifestyles)]. Voprosy istorii estestvoznaniya i tekhniki, vol. 38, no 4, pp. 756-770.

Rozhdestvenskaya E.Yu. (2019) Akademicheskaya zhenskaya kar'era: balansy i disbalansy zhizni i truda [Academic Women's Careers: Life and Work Balances and Imbalances]. Monitoring of Public Opinion: Economic and Social Change, no 3, pp. 27-47.

Rhoads R.A., Gu D.Y. (2012) A Gendered Point of View on the Challenges of Women Academics in the People's Republic of China. Higher Education, vol. 63, no 6, pp. 733-750.

Robeyns I. (2003) Sen's Capability Approach and Gender Inequality: Selecting Relevant Capabilities. Feminist Economics, vol. 9, no 2-3, pp. 61-92.

Roshchin S.Yu., Zubarevich N.V. (2005) Gendernoe ravenstvo i rasshirenie prav $i$ vozmozhnostej zhenshchin $v$ kontekste celej razvitiya tysyacheletiya [Gender Equality and Extension of Women Rights in Russia within Millennium Development Goals in the Russian Federation], Moscow: UN Information Center.

Sagebiel F. (2014) Academic Women Leaders' Career and Their Potential as Gendered Organizational Change Agents. (Re)searching Scientific Careers (eds. Prpić K., van der Weijden I., Asheulova N.), Saint Petersburg: Nestor-Historia, pp. 85-114.

Schiebinger L., Schraudne M. (2011) Interdisciplinary Approaches to Achieving Gendered Innovations in Science, Medicine, and Engineering. Interdisciplinary Science Reviews, vol. 36, no 2, pp. 154-167. 
Sen A. (1995) Gender Inequality and Theories of Justice. Women, Culture and Development: A Study of Human Capabilities, New York: Oxford University Press Inc., pp. 259-273.

Shtompka P. (2017) Spravedlivost' [Justice]. Monitoring of Public Opinion: Economic and Social Change, no 6, pp. 381-399.

Shvedova N.A. (2015) Razvitie chelovecheskogo kapitala i gendernoe ravenstvo: umnaya gendernaya politika [Human Capital Development and Gender Equality: Smart Gender Policy]. Woman in Russian Society, no 3/4 (76/77), pp. 17-30.

Tarusina N.N., Isaeva E.A. (2013) Gender: nejtralizatsiya i pozitivnaya diskriminaciya: uchebnoe posobie [Gender: Neutralization and Positive Discrimination], Yaroslavl': YArGU.

Trud $i$ zanyatost' $v$ Rossii-2019 [Labour and Employment in Russia] (2019). Statistical Compendium, Moscow: Rosstat.

Voronina O.A. (ed.) (2008) Gendernoe ravenstvo v sovremennom mire: rol' natsional'nykh mekhanizmov [Gender Equality in the Modern World: The Role of National Mechanisms], Moscow: MAKS Press.

Voronina O.A. (2013) Politika gendernogo ravenstva v sovremennoj Rossii: problemy i protivorechiya [Gender Equality Policy in Modern Russia: Problems and Contradictions]. Woman in Russian Society, no 3(68), pp. 12-20.

Wengraf T. (2001) Qualitative Research Interviewing: Biographic Narrative and Semistructured Methods, Sage, Thousand Oaks, CA.

Xie Yu, Shauman K.A. (2003) Women in Science: Career Processes and Outcomes, Harvard University Press.

Zdravomyslova E.A., Temkina A.A. (2015) 12 lektsij po gendernoj sotsiologii $[12$ Lectures on Gender Sociology], Saint Petersburg: Izd-vo Evropejskogo universiteta v Sankt-Peterburge.

Zhenshchiny $i$ muzhchiny Rossii-2018 [Women and Men of Russia] (2018). Statistical Compendium, Moscow: Rosstat. 